\title{
PERIPÉCIAS DO SACI, FORMAÇÃO DOCENTE E AULAS ANTROPOFÁGICAS
}

\author{
SHENANIGANS OF SACI, TEACHER FORMATION AND ANTHROPOPHAGIC CLASSES
}

https://orcid.org/0000-0002-8650-8272 Ana Cristina de Moraes ${ }^{\mathrm{A}}$

${ }^{\text {A }}$ Universidade Estadual do Ceará (UECE), Fortaleza, CE, Brasil

Recebido em: 16 dez. 2021 | Aceito em: 13 jan. 2022

Correspondência: Ana Cristina de Moraes (cris.moraes@uece.br)

\begin{abstract}
Resumo
O texto evoca e reflete sobre o mito popular brasileiro do Saci Pererê como relevante elemento cultural e pedagógico no âmbito da formação docente. Ao problematizar a presença ou negação desta entidade cultural no âmbito da educação formal e das formações docentes, temos como objetivo primordial, analisar as potencialidades da figura mitológica do Saci como impulsionador de uma formação de docentes situada no contexto cultural brasileiro, numa perspectiva decolonial, crítica e criativa. Autores como Bourdieu (2001), Lobato (2005), Andrade (1924; 1928), Moraes (2015; 2016) Moraes \& Therrien (2018), Paiva (2018), dentre outros, compõem a fundamentação teórica deste trabalho. Por meio de um questionário online aplicado junto a seis estudantes egressos do Mestrado de dois Programas de Pós-Graduação em Educação - PPGE - situados no Nordeste do Brasil, foi possível realizar o presente estudo. Com base nos relatos e em experiências antropofágico-formativas realizadas, percebemos o quanto a presença metafórica do Saci repercute nas formações desses sujeitos, instigando-os a alimentarem-se de saberes culturais essenciais às suas intervenções pedagógicas.
\end{abstract}

Palavras-chave: Saci Pererê; Formação docente; Pedagogia antropofágica; Cultura.

\begin{abstract}
The text evokes and reflects on the popular Brazilian myth of Saci Pererê as a relevant cultural and pedagogical element in the context of teacher education. When questioning the presence or denial of this cultural entity in the context of formal education and teacher training, our primary objective is to analyze the potential of the mythological figure of Saci as a driver of teacher education situated in the Brazilian cultural context, in a decolonial, critical perspective and creative. Authors such as Bourdieu (2001), Lobato (2005), Andrade (1924, 1928), Moraes (2015, 2016) Moraes \& Therrien (2018), Paiva (2018), among others, make up the theoretical foundation of this work. Through an online questionnaire applied to six Master's graduate students from two Postgraduate Programs in Education - PPGE - located in the Northeast of Brazil, it was possible to carry out the present study. Based on the reports and on anthropophagic-formative experiences carried out, we realize how much the metaphorical presence of Saci affects the formation of these subjects, urging them to feed on cultural knowledge essential to their pedagogical interventions.
\end{abstract}

Keywords: Saci Pererê; Teacher training; Anthropophagic pedagogy; Culture. 


\section{Introdução}

Impulsiono a escrita deste texto precisamente numa data em que se comemora o dia do Saci, 31 de outubro. A muito venho ruminando e buscando compor uma proposição de formação docente que traga no seu cerne a metáfora e o sentido da presença mágica, brincante e mística do Saci, este ser tão híbrido, multicultural, brasileiro.

- "Um viva a mim!" - Grita o Saci. E dá uma gostosa gargalhada ao sair pulando com sua perna ágil, adentrando a fantástica floresta de um canto do Brasil.

Este texto intenciona instigar o leitor para a apreensão de um olhar ao mesmo tempo atento, sarcástico e crítico, no referente à figura mitológica do Saci Pererêi ${ }^{i}$, sua relevância cultural, social e a relação deste ícone brasileiro com a formação de docentes. Reflete, pois, sobre aspectos que dizem respeito à arte, à cultura e à intervenção pedagógica vistas de modo integrado, na perspectiva da ampliação do repertório cultural desses profissionais. Vislumbrase, com isso, proposições pedagógicas que sugiram uma formação que dê visibilidade às práticas antropofágicas, perspectiva esta que, se bem observado, faz parte de todo processo de produção de saberes, sejam eles científicos, artísticos, políticos etc., sendo fundamentalmente por meio do ato de nutrir-se contínua e qualitativamente, que esses saberes serão criativamente gestados. Por "Pedagogia antropofágica" (MORAES, 2015; 2016) exaltam-se todas as ações de caráter educativo que proporcionam o acesso a informações, a produtos culturais, bem como a variadas experiências estéticas, possibilitando continuamente a apreensão de conhecimentos e estimulando as pessoas a aprofundarem esses saberes através de estudos teórico-práticos, tendo em vista a dilatação de sua formação pessoal e profissional, ampliando, assim, seu repertório cultural (MORAES \& THERRIEN, 2018).

A dimensão antropofágica dessa proposta pedagógica, diz respeito à capacidade devoradora de tudo o que causa estranhamento ao sujeito, ou seja, do que para ele é novo, desconhecido e que vai sendo descoberto e engolido, proporcionando olhares diferenciados e inspiradores para a construção de saberes teóricos e práticos (BARCELOS, 2008). Essa ação antropofágica tende a desencadear processos criativos, acessibilizando diferentes saberes que conduzem os devoradores a pensar, a mobilizar-se, a pesquisar, a intervir no mundo, a sentirse e a ser. 
Num olhar antropológico, sabe-se que a antropofagia diz respeito, em seus primórdios, a ação humana de alimentar-se do outro, seja por uma necessidade fisiológica de saciar a fome ${ }^{\mathrm{ii}}$, seja ainda por atos ritualísticos espirituais ou de guerras ${ }^{\mathrm{iii}}$.

Foi no início da década de 1920 que o Movimento Modernista brasileiro atribuiu à antropofagia uma dimensão cultural no sentido do alimentar-se de elementos artístico-culturais de diferentes povos visando enriquecer-se e ampliar a própria produção artística. Um alimentarse continuamente de outra cultura, transformando a energia desse alimento em algo singular, referendando as peculiaridades da cultura local. Oswald de Andrade, um dos precursores da defesa da antropofagia cultural no Brasil no período referenciado, prescreve, irreverentemente, em seus célebres Manifestos - o da Poesia Pau-Brasil (1924) e o Antropófago (1928) proposições para a criação de uma cultura brasileira liberta das amarras de tantas imposições europeias, não no sentido de negá-la, mas no de devorá-la, fortalecendo mais ainda a rica cultura nacional, fundada principalmente nas matrizes indígena (nativa), africana e europeia.

O sentido das intenções do movimento antropofágico do País à época reflete um forte desejo de aprofundamento de identidades nacionais constituídas pelos processos de hibridação cultural (CANCLINI, 2008) desde o processo de colonização.

Oswald de Andrade, em seu Manifesto Antropófago (1928), expõe, irreverentemente, o espírito das práticas antropofágicas, ao "comer" todos os saberes que interessam do outro para o enriquecimento cultural de seu povo. O pensamento antropofágico traz, por princípio, a prática devoradora de algo que mobiliza, que gera estranhamentos, sendo isso, de acordo com Barcelos \& Silva (2008, p. 23): “[...] um dos principais desafios colocados à educação nos tempos atuais - a criação a partir da devoração do estranho, pois, em tempos tão "turbulentos", acabamos nos acomodando e optamos, muitas vezes, por guiarmo-nos por mapas já prontos, de caminhos já percorridos". Com essas reflexões, defendo a concepção de uma Pedagogia Antropofágica como forma de ampliação do repertório de saberes necessários à formação das pessoas: uma Pedagogia que agrega um conjunto de ações educativas de caráter artísticocultural mobilizadoras de sujeitos em seus processos de aprendizagem e de criação, mais propriamente no estímulo ao alimentar-se continuamente de elementos culturais diversificados que ampliam suas referências teóricas e práticas, seu repertório, tornando-os capazes de compor novos saberes.

Intenta-se ainda, junto a tudo isso, exercitar certa profanação da elaboração acadêmica (escrita e interventiva) no campo de conhecimento pedagógico, no caminho inspirador de uma Pedagogia Profana, sugerida por Bondía (2013), com suas “danças, piruetas e mascaradas” que 
anseiam por gerar potentes transgressões também no âmbito universitário à serviço das formações docentes.

Essa profanação também diz respeito às evocações de ícones, símbolos componentes de nossa brasilidade, manifestadas nas lendas, nos causos, nos cantos, nos gestos etc. E o Saci faz parte desse universo simbólico e, consequentemente, cultural. Flávio Paiva discorre sobre o termo "Saciologia" para referir-se ao "[...] estudo, a intuição, o interesse e a satisfação de vivenciar as relações de coexistência entre o real e o imaginário, desenvolvido por crianças, adolescentes, adultos e idosos no redemoinho metafórico do Saci [...]”. (PAIVA, 2018, p. 198). Essa metáfora traduzida no mito do Saci, é aqui apreendida como elemento imprescindível para se pensar e propor uma formação docente que reconheça aspectos culturais que fortaleçam o sentimento de pertença e a mobilização de ideias, valores e práticas de apropriação da cultura brasileira.

A discussão realizada neste artigo tem por base autores como Bourdieu (2001), Lobato (2005), Andrade (1924, 1928), Moraes (2015, 2016) Moraes \& Therrien (2018), Paiva (2018), dentre outros. Além disso, apresenta e dialoga com narrativas de seis egressos/as de dois Programas de Pós-Graduação em Educação - PPGE - cursos de Mestrado acadêmico situados no Nordeste do Brasil ${ }^{\text {iv }}$. Os/as seis colaboradores/as deste estudo tiveram suas identidades preservadas, escolhendo codinomes - Cuca, Icas, Estrela Brilhante, Cisa, Onça e Anastácia Livre - para que suas respostas sejam identificadas. O curioso é que dois destes/as colaboradores/as utilizaram-se das letras do nome Saci para criar seus codinomes: Icas e Cisa. E uma se intitulou Cuca, outra importante personagem de Monteiro Lobato. Interferência direta da aura brincante do Saci Pererê.

\section{O antropofágico saci}

E o Saci, onde anda fazendo suas traquinagens? Hoje, dia 31 de outubro, no instante de continuidade de escritura deste texto, algo me incomoda profundamente: a quase ausência da figura do Saci nos holofotes midiáticos de nossa sociedade. E também nas escolas, que, em vez de celebrar seu dia, comemora-se festivamente, o Halloween, festa tipicamente norteamericana, mas que adentra - assustadoramente - os ambientes escolares, o comércio, os meios de comunicação e o universo cultural de crianças, adolescentes e adultos.

Na rua, numa cidade do litoral cearense, neste dia 31, deparo-me com grupos de crianças fantasiadas, brincando de assustar as pessoas, fazendo menção a todas as atitudes de um festejo 
importado dos Estados Unidos da América - EUA, a despeito de nossos mitos populares, que mais parecem estar enterrados no cemitério macabro sob o qual o Halloween acontece.

O Saci, entidade excêntrica que tão bem poderia estar na cena brincante, nas ruas e nas escolas comemorando seu dia no Brasil, foi ofuscado por uma onda neocolonizadora que traz o Halloween como opção única e fantástica. Relevante se faz, então, confrontar esta investida imperialista norte-americana em nossa cultura e evocar o Saci, para boicotar ou mesmo inserirse num evento do Halloween, trazendo muitas, mas muitas travessuras, que o Saci sabe fazer tão bem! Que o Saci surrupie os doces! Que esconda as máscaras dos Jasons, Jacks e whitches e espalhe em seu redemoinho seus gorros, cachimbos, energias criativas e peripécias!

- "Travessuras ou travessuras?" - Pergunta o Saci, nos ouvidos das criancinhas fantasiadas. E segue adiante, com seus pulos e estridente gargalhada.

Dizem as boas línguas e também reza a lenda que os sacis nascem em brotos de bambus, onde vivem sete anos e, após esse tempo, vivem mais setenta e sete anos para atentar a vida dos humanos e animais, depois morrem e viram um cogumelo venenoso ou uma planta chamada orelha de pau.

Dizem ainda que o Saci está nos redemoinhos de vento e pode ser capturado jogandose uma peneira sobre esses redemoinhos. Após a captura, deve-se retirar o capuz da criatura para garantir sua obediência e prendê-lo em uma garrafa.

Historicamente, o menino Saci é um ser que se hibridiza e se transforma. Originário de tribos indígenas - na figura de um curumim endiabrado, seu tipo físico é o de um garoto moreno, com duas pernas e um rabo. Com o processo de colonização e a consequente vinda de povos africanos escravizados ao Brasil, o Saci torna-se negro, no lendário universo imaginativo, perdendo uma perna jogando capoeira. Sua figura também ganha um gorro vermelho por influência de mitos europeus. Assim, de modo híbrido e brincante, o Saci vai se constituindo ao longo da história cultural brasileira: "A origem do saci é o ato imaginativo, a travessura e o espanto, como experiência lúdica e mítica” (PAIVA, 2018, p. 198).

O cachimbo que sempre acompanha o Saci e o seu hábito de fumar, parece provir de cultos ancestrais dos indígenas; as baforadas que ele dá, são sempre cercadas de grande poder místico, ao mesmo tempo misterioso e risível, como bem expunha Monteiro Lobatov ${ }^{\mathrm{v}}$, ao eternizar essa figura lendária em sua obra literária, transformada em programa televisivo, o Sítio do Picapau Amarelovi .

Outros atributos que delineiam a imagem do Saci Pererê é sua cor de pele, negra, bem como sua deficiência física, pelo fato de ter apenas uma perna. Estes aspectos me remete à 
reflexões a respeito do corpo do Saci visto pelo "outro" (SILVA, 2008), marcando sua identidade, ao mesmo tempo que sua diferença - quando se pode, por exemplo, refletir sobre questões raciais e também assuntos que envolvem deficiência física, inclusão e acessibilidade. Nesse debate, as relações de poder que o permeia, como esclarece o mesmo autor:

A identidade, tal como a diferença, é uma relação social. Isso significa que sua definição - discursiva e linguística - está sujeita a vetores de força, a relações de poder. Elas não são simplesmente definidas; elas são impostas. Elas não convivem harmoniosamente, lado a lado, em um campo sem hierarquias; elas são disputadas (SILVA, 2008, p.81).

Numa cultura que ainda possui valores bastante amarrados à lógica eurocêntrica - que tem como parâmetro o corpo branco, alto, magro, etc. e, claro, com duas pernas - não há um lugar favorável e de acolhimento para o Saci. Muito provavelmente, a quase ausência desta figura nos festejos e imaginário coletivo brasileiro se dê por conta destes atributos, sempre carregados de estereótipos e preconceitos. Normaliza-se uma verdade sobre o que seja um corpo aceito, belo e saudável, negando-se, assim, arbitrariamente, a diversidade étnica, cultural e física.

\begin{abstract}
A normalização é um dos processos mais sutis pelos quais o poder se manifesta no campo da identidade e da diferença. Normalizar significa eleger - arbitrariamente uma identidade específica como parâmetro em relação ao qual as outras identidades são avaliadas e hierarquizadas. Normalizar significa atribuir a essa identidade todas as características positivas possíveis, em relação às quais as outras identidades só podem ser avaliadas de forma negativa" (SILVA, 2008, p. 83).
\end{abstract}

Nesse caminho, reverencio a perspectiva decolonial (MENDES \& FONSECA, 2020), que pode-se definir como uma escola de pensamento utilizada essencialmente pelo movimento latino-americano emergente que tem como objetivo libertar a produção de conhecimento da episteme eurocêntrica. Ao criticar a suposta universalidade atribuída ao conhecimento ocidental e o predomínio da cultura ocidental, as perspectivas decoloniais veem essa hegemonia como sendo uma base fundante do imperialismo.

Sabe-se que o termo decolonial emergiu como um movimento de contraposição inerente ao próprio contexto de colonialidade. Diferenciando-se do termo descolonização, Santos (2018) explica que descolonial são formas de se contrapor ao colonialismo.

Decolonialidade é, segundo Balestrin (2013), um termo primordialmente usado por um movimento latino-americano emergente que empreendeu esforços para a compreensão da modernidade no contexto da teoria crítica aplicada aos estudos étnicos e, também, aos estudos de gênero. Toda a reflexão e intervenções cotidianas permeadas pela lógica decolonial precisa estar amparada pelo espírito de luta de todos que possuem princípios éticos e que se contrapõem 
radicalmente à toda forma de opressão e desrespeito aos direitos humanos e sociais. "A luta, realmente precisa ser constante, [...]. Em várias situações do dia a dia, resquícios dessa dominação são observados em toda parte, principalmente no que se refere ao preconceito racial, que perpassa pelas manifestações linguísticas até se expressar também na forma de vestir, agir e pensar" (SILVA, 2021, p. 94). Reflexo direto da referida imposição de uma cultura euro centrada, que institui hierarquias entre povos distintos, com seus saberes e práticas peculiares, porém tão relevantes quanto as outras (OLIVEIRA, 2017).

As colaborações dos sujeitos desta pesquisa, são bastante reveladoras da presença do Saci em vivências desde a infância, seja ouvindo histórias oralmente, seja assistindo ao programa televisivo baseado na obra de Lobato - Sítio do Picapau Amarelo - bem como pela experiência lendária que ronda o imaginário individual e coletivo das pessoas. Ao serem indagadas/os sobre se o Saci Pererê evoca a eles/as alguma reflexão ou experiência, leem-se os seguintes relatos:

Sim, inúmeras. Lembro-me das histórias que minha avó contava a noite e das inquietações e sensações que essas narrativas me causavam. Hoje, percebo que a cultura popular tem se perdido no tempo, pouco se estimula a falar sobre essas lendas e contos; no meu processo formativo sinto essas lacunas culturais (Cuca).

Apenas a uma lenda (Icas).

Sim! Por se tratar de um menino travesso, que leva a vida buscando deixar seus dias mais leves, o Saci traz em sua essência muito do que é ser brasileiro (Estrela Brilhante).

Quando penso no Saci, automaticamente, acesso em minha memória o "Sitio do Picapau Amarelo"; quando pequena, amava assistir na Tv e viajar com as histórias do Sítio. Acompanhei a $2^{a}$ versão. Lembro muito do Saci e de suas histórias através do Sítio (Cisa).

A primeira memória que tenho do Saci é da obra do Sítio do Pica-pau amarelo. Depois, quando eu morei na cidade de Jaguaribe-CE durante minha infância, meu avô me contava histórias do Saci como se fosse uma pessoa real, relatos de outras pessoas que haviam presenciado sua aparição. Como a de funcionários da fazenda que tinham que deixar cigarro e fumo em determinados locais para que o Saci não escondesse ferramentas de trabalho ou desse susto neles durante a noite. Ele contava muitas histórias, à noite, no alpendre da fazenda onde morávamos e ficava apontando luzes na estrada dizendo que eram os olhos do Saci olhando pra gente. Tenso... (Onça).

A ousadia é a protagonista de suas incursões. Acessar os medos e me "fazer aparecer" como protagonista de meu próprio processo é a sua maior marca e presença constante em minhas reflexões e escritos (Anastácia Livre).

Histórias narradas por entes familiares, muitas vezes, deixam a memória marcada por saberes significativos, em especial se se trata de lendas ou causos que são contados por várias gerações. Em meio às respostas, duas delas assinalam o programa televisivo Sítio do Picapau Amarelo, que fez parte do universo cultural de, pelo menos, três gerações de crianças e adolescentes e que foi uma relevante possibilidade de se mergulhar na obra literária e 
personagens de Monteiro Lobato, que tanto valorizou os mitos, lendas e variadas manifestações da cultura brasileira.

O Saci, como realça a colaboradora Anastácia Livre, tem como forte característica a ousadia, que "é a protagonista de suas incursões". Sendo que esse espírito ousado do Saci muito a inspira em suas reflexões e escrita. É esse espírito ousado, alegre, criativo, por isto transgressor, que desejo semear nas formações docentes.

- “Traz mais fumo, porque meu cachimbo está apagando!" - Alerta o Saci em tom ameaçador, envolto em uma nuvem de fumaça. E logo desaparece em meio a ela.

\section{Por uma formação docente que evoque o mito do Saci (esquecido?)}

Fazer emergir a figura mitológica do Saci no âmbito de proposições formativas de docentes é trazer à tona a velha reflexão que confronta o suposto binômio razão versus mito. É abrir espaço para outras dimensões do conhecimento humano e que são tão essenciais quanto a dimensão racional. Do que se vivencia no atual contexto de desenvolvimento capitalista: "Tudo aquilo que era considerado excepcional no mundo primitivo, foi banido pelos homens modernos, que se empenharam na construção de uma existência onde seres e coisas tornaramse disponíveis, utilizáveis e consumíveis" (PEREIRA, 2004, p. 55). Considero, pois, urgente, o escancaramento da intrínseca relação entre os universos racional, onírico, sentimental, imaginativo, espiritual, caótico etc. Sendo o ser humano um sujeito complexo, integral, não se pode prescindir de um olhar total sobre ele. Infelizmente, o que se verifica é uma constante tentativa de fragmentar esse sujeito, tornando-o cada vez mais objetificado, como peça útil na engrenagem do capital, que vivifica a sociedade de produção e consumo. Tudo parece girar em torno da necessidade econômica imediata. Nossa dimensão simbólica e imaginativa vem perdendo força nesse jogo duro, da objetividade produtiva e que hiper dimensiona a vida ordinária: "O deslocamento da percepção que houve na modernidade com relação aos nossos medos saiu do plano extraordinário para ser um problema simplesmente real (PAIVA, 2018, p. 199).

Em aulas de Mestrado Acadêmico em Educação e Ensino, especificamente nas disciplinas Escola, Currículo e Democracia (com vinte mestrandos/as) e na de Estudos Orientados (com cinco mestrandos/as) - em experiências realizadas presencialmente em 2019 - foi discutido sobre a lenda do Saci Pererê, sua energia brincante, mística e multirreferenciada em culturas de povos antepassados, tecendo-se relações com uma formação de docentes mergulhada nesses saberes lendários, com a perspectiva de instigarmos um sentimento de 
pertencimento cultural desses docentes, bem como de criarmos proposições pedagógicas que possam evocar a figura mitológica do Saci nos variados espaços educativos.

A partir de leituras de textos de autores que discutem "saciologicamente" (PAIVA, 2018); (LOBATO, 2005), levei para a sala de aula e entreguei a cada estudante alguns artefatos que visavam instigar a garantia da presencialidade do Saci e sua aura brincante, traquina, como saquinhos de pano vermelho com cachimbos, bolas de gude, chumaços de algodão - que lembravam o redemoinho de poeira que trazia o Saci, etc. além de livros que faziam referência a este ser mítico. Tudo era motivo para ampliarmos as conversas e para explorarmos nossa memória, relacionando ideias a qualquer fato que o referenciava. Lembranças de vivências de infância, histórias ouvidas e contadas por adultos, festejos escolares e brincadeiras que tinham a figura do Saci; tudo funcionava como importante dispositivo para pensar-constituir as formações docentes calcadas em elementos da cultura brasileira, suas lendas e matrizes.

Nesse encontro específico sobre o universo do Saci, muitas discussões e questionamentos foram feitos: o Brasil possui uma baixa autoestima cultural que faz com que não abracemos nossos próprios mitos? A bruxa do outro é mais malévola e atraente? Por que o festejo do Halloween vem se manifestando de modo tão potente no Brasil, inclusive com legitimação das escolas, comércios e meios de comunicação?

Em meio a esses questionamentos, discutimos sobre o quão forte é o chamado "poder simbólico" (BOURDIEU, 2001), que pressupõe um conformismo lógico, uma homogeneização de pensamentos e práticas que geram concordância e cumplicidade entre saberes por meio de símbolos culturais. Para Bourdieu (2001, p. 07-08) “o poder simbólico é, com efeito, esse poder invisível o qual só pode ser exercido com a cumplicidade daqueles que não querem saber que lhe estão sujeitos ou mesmo que o exercem". As práticas culturais que vão sendo incorporadas são impulsionadas também pelos meios de comunicação que impõem produtos e envolve a todos numa lógica consumista desenfreada, irracional, o que vai gestando uma outra cultura, um modismo que deseja se perpetuar. Nesse mesmo caminho reflexivo, Paiva (2018, p. 203), realça que "[...] a configuração do nosso pensamento é construída e manipulada pelos sistemas simbólicos que são empregados como modelos de outros sistemas.” (PAIVA, p. 203).

Esse histórico processo de aculturação atinge a cultura brasileira de modo arrebatador, por utilizar-se de estratégias simbólicas, muitas vezes sutis e até envolventes: “[...] Os processos de aculturação em ampla medida são violências, sem que para tanto se tenham necessariamente usado armas" (MORAIS, 2002). Este autor complementa ainda que, ao termos nossas bases de reconhecimento, valorização e afirmação cultural fragilizadas, a tendência é a de 
aprofundamento do processo de aculturação: “[...] No contato cultural incipiente, a cultura mais frágil é submetida a situações tão incômodas, que acaba rendendo-se a formas de acomodação que não passam de expedientes para se autopreservarem [...]” (MORAIS, p. 17, 2002). Nesse contexto, o Saci Pererê perde espaço para as lendárias figuras norte-americanas do Halloween.

[...] cada vez vemos com mais nitidez posturas culturais fechadas que tudo fazem para negar a validade de modo de viver de outros povos, ou mais discretamente pela afirmação demasiado enfática de seus próprios valores, ou mais agressivamente pela acusação de atraso e inaceitabilidade dos valores alheios (MORAIS, p. 22, 2002).

O Saci está aqui? Ou preso na garrafa? O dia 31 de outubro no Brasil, foi instituído como o dia do Saci. Alguns estados e municípios formalizam esta data em seus calendários oficiais como forma de realçar este mito na tradição e cultura brasileira. Felizmente, estas iniciativas institucionais ajudam na preservação e no estímulo do conhecimento e da valorização dos saberes culturais de tradição, como as lendas. No Estado do Ceará, por exemplo, esta data está inscrita no calendário oficial do Estado. Na capital - Fortaleza - Paiva (2018, p. 202) assinala que: "A Câmara Municipal de Fortaleza, a exemplo de outras cidades, criou o Dia do Saci no município, com votação simbolicamente realizada no dia 31 de outubro de 2007'. E enfatiza ainda que:

A reversão das estruturas simbólicas identificada na revitalização do Saci Pererê, como anti-herói da negação do consumismo e da massificação, recomenda respeito à abordagem empírica que circunda as questões-chave da atualidade e reformula o debate em um plano que privilegia o olhar da sociedade civil (PAIVA, 2018, p. 204).

Nesse caminho, corroboramos com Paiva (2018) na fervorosa busca do Saci e na incorporação desta entidade mitológica em nossas práticas pedagógicas e no nosso repertório de saberes e afetos.

\section{Identificando-se com o Saci: proposições para uma formação docente}

Com esteio nos relatos de egressos/as colaboradores/as, teço algumas reflexões propositivas a respeito de possibilidades formativas de docentes.

Num primeiro raio de reflexão, remeto-me à necessária rede de parcerias de pessoas sintonizadas pelo sentimento de pertença e valorização de manifestações da cultura brasileira, essenciais para o fomento do diálogo e das ações conjuntas no que diz respeito à incorporação de práticas pedagógicas, especial e primordialmente, no âmbito da formação docente. A base formativa desses/as profissionais precisa estar alicerçada em saberes culturais fortes, que garantam amplo e sólido repertório a eles/as, para que, assim, tenhamos possibilidades concretas de desenvolver trabalhos educativos que evoquem nossos mitos, crenças, lendas, 
manifestações culturais que façam com que sujeitos aprendentes se sintam pertencentes a uma comunidade, mergulhados em um contexto carregado de valores, símbolos e potência sensível.

Em conjunto, tecemos teias de ideias capazes de criar lugares para o Saci hoje, seja por meio de estratégias que gerem relatos e registros de lembranças e associações simbólicas entre o Saci e cada sujeito, seja ainda por meio de práticas escolares e universitárias que estimulem presenças mais constantes de saberes culturais de tradição com o intuito de fazê-los conhecer, abraçar e garantir seu alcance e preservação por gerações vindouras.

No referente à formação docente, indaguei às/aos egressas/os: que elementos da figura mitológica do Saci você apreende como essencial à sua atuação pedagógica? Inscrevem-se as seguintes respostas:

A estimulação da imaginação, criatividade e inserção da cultura popular dentro do contexto educacional. É difícil, as vezes, já que envolve um processo e a necessidade de travar diálogos com a prática. A figura do Saci me remete a uma pessoa que possui elementos transgressores também, o que percebo como sendo essencial; às vezes é necessário ir contra a maré e defender os nossos ideais, principalmente em tempos sociopolíticos tão caóticos (Cuca).

A questão cultural que há em relação à história da mitologia do Saci (Icas).

A criatividade, o brincante e a forma alegre de desenvolver as coisas (Estrela Brilhante).

Penso que a aproximação; a figura/mito do Saci nos aproxima da nossa cultura, histórias, lendas, nos aproxima de nossas origens (Cisa).

No meu imaginário, o Saci é um ser que faz muitas travessuras. Não me vejo como uma professora travessa, mas consigo associar muitos alunos que tive com o comportamento do Saci (Onça).

Adentrar uma mata fechada, no submundo de referências e escritos atuais, anteriores e/ou presságios intelectuais é um desafio constante, além de se permitir compreender e ressignificar esses processos de saberes distintos. Nas clareiras dessa mata, o lançar-se a desvelamentos pedagógicos e malabarismos didáticos torna-se viciante, e o momento da experiência é cheio de sentidos, transcendem à verbalização, à oralidade, é algo visceral, libertador e transformador. Para o exercício de adentrar nessa mata de saberes pulsantes há de se render às subversões do Saci, pensar possibilidades lógicas e ao mesmo tempo subjetivas, não cessar a curiosidade de aprendente no processo individual e coletivo do existir. Pesquisar, refletir e ação em conexão com o presente é um movimento essencial à ação docente (Anastácia Livre).

Evocar o imaginário, transgredir enquadramentos didáticos, mergulhar em nossa cultura, valorizar e exercer traquinagens inspiradas no Saci são alguns dos elementos presentes nas falas dos/as egressos/as, mestres/as em Educação. Por estes relatos, percebe-se a potência simbólica que a figura do Saci tende a exercer no âmbito da formação e da atuação de docentes. E é com esta perspectiva brincante, criativa, transgressora e plural que vislumbro um projeto formativo para estes/as profissionais, especialmente alicerçado em saberes culturais brasileiros. 
- “Tirem-me da garrafa! Quem foi o malvado que me deixou preso aqui dentro?" Indaga o Saci, endiabrado.

A respeito de aulas no Mestrado nos dois PPGE citados, em que tivemos o Saci Pererê como dispositivo propulsor de reflexões e práticas formativas, indaguei às/aos colaboradoras/es: que saberes você considera ter apreendido/mobilizado? Discorra sobre essa(s) aula(s).

O saber da cultura popular inserida na dinâmica da educação; a dimensão criativa e estética do saber (Cuca).

Despertou para as brincadeiras. O lado criança que todos devem ter um pouco (Icas).

Primeiramente o quão rica é a nossa cultura! Perceber que o currículo pode ser um elemento basilar para conhecermos nossas raízes, foi um elemento importante nas nossas aulas. O fato de estudar um pouco da história do Saci, nos mostrou a importância de termos essas experiências em sala de aula (Estrela Brilhante).

Recordo que nas aulas pude adentrar na história do Saci de uma forma que eu não tinha muito conhecimento, conheci as outras versões do Saci. Foi curioso e instigante mergulhar nesse mito e com um cachimbo e outros objetos disponíveis na aula a experiência se tornou mais sensível (Cisa).

Acredito que para além da travessura, o Saci é um ser que emerge das florestas para cuidá-las. Então é um ser que merece respeito, tanto pelo fato de proteger a natureza como também por ser meio vingativo e gostar de pregar peças nas pessoas, como diz a lenda (Onça).

A mobilização para a subversão, pensar criativamente e propor outras possibilidades. Construir de modo coletivo novas perspectivas de saberes, refletir sobre as práticas pedagógicas e perceber em minhas vivências o fio que norteará meus percursos. Seguir e tonar os pontos surgidos no caminho, para ressignificar aprendizagens e redescobrir outros sentidos. Ampliar minha perspectiva de docente, para uma possibilidade como pesquisadora e propositora de outras ações pedagógicas. Perder o medo de ser e existir. Trocar o questionamento: "Será que posso?", pelo imperativo: "Eu posso!" (Anastácia Livre).

As falas realçam a dimensão brincante, lúdica e a valorização da cultura popular brasileira como aspectos essenciais nas aulas em que foram trazidos saberes lendários, particularmente referentes ao Saci. Além disso, foi lembrado o quanto o Saci traz a ideia da paixão e da proteção das matas, seu berço e sua casa. Aspecto este que aponta, nas práticas educacionais, a perspectiva da educação ambiental e da consciência ecológica.

Outro elemento presente no relato de Estrela Brilhante é o realce dado à importância dos currículos referendarem elementos culturais que retratem a cultura brasileira, o que Silva (2010) tanto enfatiza, na perspectiva dos estudos culturais, considerando o currículo um instrumento ao mesmo tempo poético e político.

Interessante se faz destacar que, nos diálogos em sala de aula, ao menos discursivamente, a tônica da valorização das manifestações culturais brasileiras se fez muito presente. Esse exercício discursivo e dialogado representa, a meu ver, um passo essencial ao 
desenvolvimento do sentimento de pertença e de transcendência do olhar colonizado ainda tão impregnado em muitos de nós.

[...] o ensino precisa eliminar o abismo entre os conhecimentos estudados e a realidade dos alunos, por isso, a Didática flexionada como política possibilita uma descolonização do ensino a fim de ligá-lo cada vez mais às situações de vida, saberes e interesses locais para que o aluno possa ensaiar suas próprias formas de libertação da colonialidade, o que exige um testemunho ético por parte do professor (CHAVES, 2021, p. 172).

Como última questão, solicitei às/aos colaboradoras/es deste estudo que escrevesse uma ideia ou frase que tenha a ver com a dimensão brincante, transgressora e criativa do Saci Pererê.

Convocaram o Saci que habita em mim, então vamos lá: gosto de ver o rebuliço acontecer, de pregar peça e brincar. Gosto de sumir, de fumar meu cachimbo e fazer bagunça. Mas não vá achando que aceito qualquer coisa, pera lá! Se for para gostar de mito que seja de nós da cultura popular. O resto é só invenção, história para povo besta acreditar (Cuca).

Saci já é uma figura muito hilariante com apenas uma perna, imagine com as duas! (Icas)

A educação deve estar sempre intimamente ligada às ideias travessas do Saci, ou seja, deve proporcionar aos educandos, práticas educativas permeadas de criatividade e divertimentos, para que assim, torne-se cada vez mais atrativa (Estrela Brilhante).

Que o brincar não seja ontem, não seja passado; o brincar é presente e futuro. Que possamos aguçar e ser o brincante que habita em nós (Cisa).

Que possamos continuar perpetuando esses mitos de maneira didática e educativa, não somente em sala de aula, para que nossos aspectos culturais não desapareçam com as gerações posteriores à nossa (Onça).

A observação lúdica para si, permite compreender com clareza de ideias e nos mobiliza na dimensão do "ir além" nas possibilidades cotidianas. Aquieta-se nos desafios, fortalece-se nos nãos recebidos e resiste, transformando o comum no surreal (Anastácia Livre).

A alegria, bagunça e traquinagem do Saci estão, nestas falas, bastante presentes. A dimensão lúdica das pessoas clama por este universo brincante. E o Saci tende a encantar por essa característica tão aguçada em si. No campo da ação pedagógica, essa dimensão precisa ser mobilizada constantemente, pois o poder do ato criativo, inusitado, risível, das atitudes que mexem com os sentidos humanos, trazem muita potência às ações pedagógicas, pois funcionam como um convite à aprendizagem, um chamamento à aventura de conhecer e vivenciar os saberes culturais.

Como proposição para um dia 31 de outubro brasileiro, ecoo um grito de viva ao Saci! Um contraponto à tentativa de tornar hegemônico o festejo do Halloween em nosso país. A interação entre essas elaborações culturais podem e devem existir, não como sobreposição de uma sobre outra, mas como valorização e destaque da memória, da valorização dos mitos e 
símbolos do Brasil, pois isso tende a fortalecer as identidades, potencializar o imaginário e a autoestima coletiva

Considero ser fundamental a autovalorização, o auto reconhecimento cultural em toda proposição formativa de docentes, pois, pode-se contribuir muito com a pluralidade cultural a partir dessa apropriação e abertura para valorizar-se e dialogar com o outro.

Escola e universidade constituem campos extremamente férteis para o diálogo e a problematização acerca das diferenças. Todas as crianças hoje passam (ou deveriam, legalmente, passar) pela escola. Poderão ser futuros adultos mais abertos ao diálogo, se estimulados a mergulharem e a abraçarem sua cultura. Docentes têm aí um espaço político essencial para a sua práxis pedagógica. Dialogar com o diferente nos remete a uma perspectiva ética - sou diferente e possibilito que o outro também seja. Daí a necessidade da alteridade princípio ético elementar - na garantia da convivialidade. Toda reflexão ética é busca de se atingir um ideal. Esse ideal, a meu ver, não tem a pretensão de ser homogeneizador. Isso estaria, assim, negando a própria condição de diversidade.

\section{Considerações finais}

A figura mitológica do Saci aponta caminhos pedagógicos de grande potência simbólica, político-pedagógica, brincante e que remete à diversidade cultural brasileira. Ao trazer à tona as reflexões sobre diversidade, identidades e diferenças nos contextos de formação docente, com foco em símbolos referenciados na cultura em que esses docentes fazem parte, um projeto formativo poderá instigá-los a multiplicar esses saberes nas escolas e universidades em que atuam, fortalecendo, com isso, uma perspectiva de educação complexa, decolonial, ética e estética.

Diversidade é fato! Seja no âmbito de toda a biodiversidade, dentro de uma espécie, entre espécies e entre ecossistemas. Esta não é uma discussão tão recente no âmbito das Ciências Naturais, mas no que se refere ao campo da Cultura e Educação, de certa forma, sim. A discussão sobre diversidade cultural estrutura-se, principalmente, nas três últimas décadas. Para isto ocorrer, grande impulso foi dado pelos Novos Movimentos Sociais - pelas suas capacidades de crítica social e diante de tantas demandas específicas por políticas públicas e por conquistas de direitos, de respeito e de visibilidade às diferenças. Diferenças essas que foram e são historicamente negadas e oprimidas, a exemplo do etnocentrismo, das variadas atitudes de intolerância e violências a pessoas negras, indígenas, imigrantes etc. 
Ao/à educador/a, é imprescindível pensar e abraçar a diversidade, no sentido de possibilitar o diálogo e a problematização no âmbito das diferenças. Sendo importante indagar, continuamente: como essas diferenças são produzidas? Quem produz essas diferenças? Quem consagra o que é diferente? Que relações de poder as permeiam?

Tendo-se claro que todo processo educativo nessa empreitada de evocação do Saci, com tudo o que seu universo simbólico, seu corpo e sua metáfora mobiliza, representa um esforço de desnaturalização, de desmecanização de verdades instituídas. Esse processo precisa, pois, apontar a mutabilidade e a complexidade das realidades.

Todas essas proposições requerem, pois, educação estética (MORAES, 2016), para ampliarem suas percepções ao fato de que a valorização e produção cultural são elementos vitais para a sociedade, vitais no sentido mais profundo, no âmbito da manifestação da busca de uma fortaleza desta cultura e de uma beleza ${ }^{\text {vii }}$ comportamental.

Não há, pois, projeto educativo que não esteja permeado por uma militância políticopedagógica, sendo que isso envolve desejo de transformação sociocultural, articulações e negociações no complexo jogo de força da cena política. Assim, é bem mais promissor projetar uma educação estética com potência para contribuir com a formação das sensibilidades das pessoas, que tentar negar ou fugir desse jogo político. Principalmente porque o atual contexto reclama, ao mesmo tempo, atitudes denunciadoras e anunciadoras, para utilizarmos os termos de Freire (2006). Anúncio de um projeto formativo que reverencie o Saci e que, nele inspirado, proporcione uma formação docente, similarmente travessa e encantadora.

\section{Referências}

ANDRADE. Oswald. O Manifesto Poesia Pau-Brasil. Jornal Correio da Manhã. São Paulo, março, 1924.

ANDRADE. Oswald. Manifesto Antropófago. Revista de Antropofagia. Piratininga, ano I, n. 1, maio 1928 .

BALLESTRIN, L. América Latina e o giro decolonial. Revista Brasileira de Ciência Política, Brasília, n. 11, p. 89-117, 2013.

BARCELOS, Valdo; SILVA, Ivete S. Antropofagia cultural brasileira e educação contribuições ecologistas para uma pedagogia da "devoração". Revista Poiesis, v. 1, n. 1, p. 20-41, jan./abr. 2008.

BONDÍA, Jorge L. Pedagogia profana: danças, piruetas e mascaradas. 5. Ed. Belo Horizonte: Autêntica, 2013. 
BOURDIEU, Pierre. O Poder Simbólico. Rio de Janeiro: Bertrand Brasil, 2001.

CANCLINI, Nestor G. Culturas Híbridas: estratégias para entrar e sair da modernidade. São Paulo: EDUSP, 2008.

CHAVES, Pedro J. Didática, decolonialidade e epistemologias do Sul: uma proposta insurgente contra a neoliberalização do ensino escolar e universitário. Curitiba: CRV, 2021.

DURAND, Gilbert. As estruturas antropológicas do imaginário. São Paulo: WMF Martins Fontes, 2012.

FREIRE, Paulo. Pedagogia da Autonomia: saberes necessários à prática educativa. São Paulo: Paz e Terra, 2006.

LOBATO, Monteiro. O Saci. São Paulo: Brasiliense, 2005.

MENDES, Gabriela da S.; FONSECA, Alexandre B. C. da. A questão de gênero numa perspectiva decolonial. Revista Educação Pupilar, Uberlândia, v. 19, n. 1, p. 82-101, jan./abr. 2020.

MORAES, Ana C. Pedagogia Antropofágica: Diálogos. Fortaleza: EdUece, 2015.

MORAES, Ana C. Educação Estética na Universidade: antropofagias e repertórios artístico-culturais de estudantes. Fortaleza: EdUece, 2016.

MORAES, Ana C.; Therrien, Jacques. Pedagogia antropofágica no aprofundamento do repertório de saberes culturais de estudantes de Pedagogia e seus professores. Eccos revista científica, São Paulo, n. 46, p. 53-69, mai./ago. 2018.

MORAIS, Regis. Cultura Brasileira e Educação. Campinas-SP: Papirus, 2002. OLIVEIRA, Rosana M. Descolonizar os livros didáticos: raça, gênero e colonialidade nos livros de educação do campo. Revista Brasileira de Educação, Brasília, v. 22, n. 68, p. 1133, jan./mar. 2017.

PAIVA, Flavio. Saciologia Brasileira. In: SOARES, Cristina; SIEBRA, L. M. Gonçalves;

ALMEIDA, M. T. Pinheiro; BATISTA, V. Louise (Orgs.). Escola: lugar de brincadeira, cultura e diversidade. Fortaleza: Editora Imprece, 2018. p. 197-204.

PEREIRA, Ondina. No horizonte do outro. Editora Universa-UCB: Brasília, 2004.

SANTOS, Vivian M. dos. Notas desobedientes: decolonialidade e a contribuição para a crítica feminista à ciência. Psicologia \& Sociedade-UNOESC, Belo Horizonte, v. 30, p. 2-11, 2018.

SCHILLER, Friedrich. A Educação estética do homem. São Paulo: Iluminuras, 2011.

SILVA, Tomaz T. (Org.). Identidade e diferença: a perspectiva dos estudos culturais. Petrópolis-RJ: Vozes, 2008. 
SILVA, Tomaz T. O currículo como fetiche: a poética e a política do texto curricular. Belo Horizonte: autêntica Editora, 2010.

SILVA, João P. Estágio supervisionado na formação inicial de docentes: reflexões sobre a inserção de alunos estrangeiros no curso de letras da UNILAB. 2021. 160 f. Dissertação (Mestrado Acadêmico em Educação e Ensino) - Faculdade de Filosofia Dom Aureliano Matos, Universidade Estadual do Ceará. 2021. 160 f. Disponível em: https://siduece.uece.br/siduece/trabalhoAcademicoPublico.jsf?id=101353. Acesso em: 15 de setembro de 2021.

\footnotetext{
${ }^{\text {i }}$ Compreende-se por mito o sistema de constituição dinâmica de símbolos, arquétipos e imagens que, em geral, se traduzem em narrativas. Para G. Durand (2012), o mito surge como um relato que põe em cena personagens, cenários, objetos simbolicamente valorizados, nos quais se investe, necessariamente, uma crença.

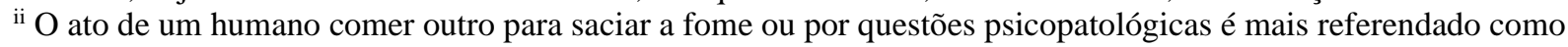
canibalismo e não como antropofagia, para diversos autores.

iii Nessa direção, o antropólogo Darcy Ribeiro investiga, baseado nas pesquisas em comunidades nativas do Brasil Ver RIBEIRO, Darcy (1995).

iv Os programas acadêmicos referidos são: Programa de Pós-graduação em Educação - PPGE - e o Mestrado Acadêmico Intercampi em Educação e Ensino - MAIE - ambos vinculados à Universidade Estadual do Ceará UECE.

${ }^{v}$ LOBATO, Monteiro. O Saci. [ilustrações de capa e miolo Manoel Victor filho]. — São Paulo: Brasiliense, 2005.

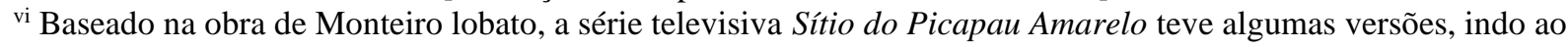
ar em canal aberto nos períodos 1977-1986; 2001-2007.

vii Beleza se insere aqui com a perspectiva desenvolvida por Schiller (2011), que atribui à educação estética o papel de formação do caráter das pessoas, tornando-o nobre e belo num sentido ético. Nessa perspectiva, beleza ou nobreza de caráter vão se aperfeiçoando com o exercício da autonomia e da liberdade consciente.
} 